\title{
Sobre a Observação enquanto Procedimento Metodológico na Análise do Comportamento: Positivismo Lógico, Operacionismo e Behaviorismo Radical
}

\author{
Alexandre Dittrich ${ }^{1}$ \\ Bruno Angelo Strapasson \\ Jocelaine Martins da Silveira \\ Paulo Roberto Abreu \\ Universidade Federal do Paraná
}

\begin{abstract}
RESUMO - A Análise do Comportamento adota duas posições distintas sobre a observação enquanto procedimento metodológico. $\mathrm{Na}$ análise experimental, tende-se a aceitar apenas a descrição de relações funcionais entre variáveis observáveis. Na análise interpretativa, contudo, relações funcionais entre variáveis observáveis e não-observáveis são inferidas. A posição da filosofia behaviorista radical sobre a questão torna-se mais clara quando examinada a partir da influência do operacionismo sobre a Psicologia, em especial nas décadas de 30 e 40 . O presente artigo propõe-se a realizar tal exame, apoiando-se na literatura dedicada ao assunto e nos escritos de Skinner. Concluiu-se que a análise de eventos privados, proposta por Skinner: (1) é de natureza interpretativa; (2) refere-se, pelo menos em parte, a eventos inobserváveis publicamente; (3) lança mão, em alguma medida, da introspecção enquanto método; (4) lança mão, em alguma medida, de inferências sobre o mundo privado do outro.
\end{abstract}

Palavras-chave: observação; Behaviorismo Radical; Análise do Comportamento; operacionismo; positivismo lógico.

\section{On Observation as a Methodological Procedure in Behavior Analysis: Logical Positivism, Operationism and Radical Behaviorism}

\begin{abstract}
Behavior Analysis adopts two distinct viewpoints about observation as a methodological procedure. In the experimental analysis, it tends to accept only the description of the functional relations among observable variables. In interpretive analysis, however, it infers functional relations among observable and unobservable variables. The radical behaviorist stance about this topic becomes clearer when examined from the influence of operationism over Psychology, especially in the 30's and 40's. This paper aims to accomplish such an examination, based on the specialized literature about the topic and on Skinner's texts. It concludes that the analysis of private events proposed by Skinner: (1) has an interpretive nature; (2) refers, partly at least, to publicly unobservable events; (3) in some measure, employs introspection as a method; (4) to a certain extent, makes inferences about the private world of the other.
\end{abstract}

Keywords: observation; Radical Behaviorism; Behavior Analysis; operationism; logical positivism.

Muitos alunos de graduação em Psicologia, ao travar contato com os princípios do Behaviorismo Radical e da Análise do Comportamento, mostram-se confusos diante do que, aparentemente, constitui uma contradição. Uma das características básicas da filosofia behaviorista radical, afirma-se, é a plena aceitação dos eventos privados como objetos de estudo legítimos em uma ciência do comportamento, a despeito do fato de que tais eventos definem-se por serem publicamente inobserváveis. Por outro lado, na análise experimental do comportamento, o behaviorista radical, via de regra, evita qualquer recurso aos eventos privados - não está interessado no que os sujeitos experimentais pensam ou sentem (sejam humanos ou não), mas sim nas relações entre respostas públicas e eventos ambientais públicos. Diante disso, perguntam os alunos: "por que os behavioristas radicais afirmam estudar os eventos privados quando, de fato, não os estudam?" Ou ainda: "em que sentido pode-se afirmar que os behavioristas radicais estudam os eventos privados?" Torna-se óbvio, desde já, que a resposta a tais questões guarda

1 Endereço para correspondência: UFPR, Departamento de Psicologia. Praça Santos Andrade, 50. Curitiba, PR. CEP 80020-300. E-mail: aledittrich@ufpr.br. relações diretas com a questão da observação dos fenômenos estudados pela Psicologia, e com a posição do Behaviorismo Radical diante do problema.

\section{Observação, Ciência e Positivismo}

Costumamos conferir à observação um grande valor enquanto forma de contactar e conhecer o mundo. Dentre todos os sentidos, a visão é, sem dúvida, aquele que destacamos enquanto revelador de um mundo "real". Ela nos permite, ao que parece, partilhar uns com os outros um mundo "impessoal", "objetivo" - um mundo que nosso corpo percebe mesmo à distância, e sobre o qual podemos construir um discurso relativamente preciso, criando conceitos passíveis de algum consenso a partir de evidências públicas. Mesmo no nível do senso comum, consideramos a observação uma espécie de juíza privilegiada do que é, ou não, verdadeiro queremos "ver para crer".

A observação foi fundamental na constituição dos métodos da ciência moderna. A invenção do telescópio por Galileu é um marco simbólico de sua importância nessa constituição 
(Gioia, 1988/2004). A ciência ainda valoriza a observação, pelo menos nas circunstâncias nas quais ela se faz possível. Porém, para parte dos filósofos e cientistas das primeiras décadas do século $\mathrm{XX}$, a observação era não apenas algo desejável, mas sim uma exigência - quase uma obsessão, poder-se-ia afirmar. Referimo-nos à filosofia denominada positivismo lógico, representada, inicialmente, pelos integrantes do Círculo de Viena, a partir da década de 20.

Caracterizar filosofias é sempre uma tarefa delicada e complexa. Interpretações diferenciadas sobre as características das diversas tradições filosóficas são inevitáveis, mas simplificações e equívocos grosseiros são ainda mais comuns. A palavra "positivismo", por exemplo, tornou-se uma espécie de ofensa, que parece resumir as mais deletérias qualidades do espírito científico, sem que se especifique exatamente o que se está criticando ${ }^{2}$. Tal constatação poderia ser pouco importante para os behavioristas radicais, não fosse o fato de que a qualificação "positivista" é frequentemente utilizada para caracterizar o próprio Behaviorismo Radical, via de regra, sob um viés crítico. Considerando que essas críticas não costumam aplicar qualquer adjetivo ao termo "positivismo”, elas sugerem, implicitamente, ou (1) que só existe uma forma de positivismo ou (2) que os behavioristas radicais são positivistas no sentido comteano - duas proposições flagrantemente falsas.

Tampouco o positivismo lógico caracteriza o Behaviorismo Radical. Não obstante, as relações entre essas filosofias são historicamente importantes para que possamos compreender as circunstâncias sob as quais surge a proposta filosófica de Skinner. Em vista disso, buscaremos delinear a seguir, ainda que de forma sucinta, o contexto histórico e as características básicas do positivismo lógico, bem como suas relações com o operacionismo e com o que se convencionou chamar de neobehaviorismo - isto é, as psicologias de E. C. Tolman, C. L. Hull e, especialmente, B. F. Skinner. Julgamos que tal discussão seja importante a fim de caracterizar o status da observação enquanto procedimento metodológico para o Behaviorismo Radical.

\section{Positivismo Lógico, Operacionismo e Psicologia}

O risco de simplificação, para o qual alertamos acima, sempre ronda aquele que se propõe a caracterizar de forma sucinta certa tradição filosófica. O positivismo lógico, como outras filosofias, viu-se representado por diversos autores, cujas opiniões, não raro, divergiram ao longo do desenvolvimento histórico dessa corrente. Não obstante, buscaremos caracterizá-la resumidamente, por sua importância para os objetivos deste trabalho.

Historicamente, conforme comentamos, o surgimento do positivismo lógico está ligado às discussões do Círculo de Viena - um grupo formado na década de 20 por filósofos e cientistas interessados em questões de ordem epistemoló-

2 Sobre isso, ver, por exemplo, Cupani (1990), em artigo no qual enumera equívocos comuns nos ataques ao positivismo. Não se trata, aqui, de defender o positivismo, em qualquer de suas variantes, mas de apontar certo descaso para com a qualidade do debate filosófico. gica, particularmente no campo da física. As discussões do Círculo foram motivadas, primariamente, pelo advento das "revoluções gêmeas da teoria da relatividade e da mecânica quântica" (Moore, 1985, p. 53). O Círculo representa uma das mais destacadas tentativas de intercâmbio intelectual entre filósofos e cientistas. Embora liderado por um filósofo (M. Schlick), o grupo era integrado também por físicos (R. Carnap, P. Frank), matemáticos (K. Gödel, H. Hahn, G. Bergmann) e mesmo representantes de campos como a economia (O. Neurath), a história (V. Kraft) e o direito (H. Kelsen).

O positivismo lógico herda do positivismo comteano a preocupação epistemológica com a enunciação de fatos empiricamente verificáveis. O adjetivo "lógico" diferencia as duas correntes. A proposta de junção das duas palavras surge em 1931, no artigo Logical Positivism: A New Movement in European Philosophy, de H. Feigl e A. Blumberg (Smith, 1986, p. 28). Um fato positivo é um fato empírico, publicamente verificável. Para os positivistas lógicos, porém, o positivismo comteano, assim como as primeiras doutrinas empiristas, restringiu-se aos aspectos biológicos, sociológicos e "perceptivos" da construção do conhecimento científico, ignorando a importância da lógica e da linguagem nesse campo (Smith, 1986, pp. 27-28)3 . Daí a importância do adjetivo "lógico" na definição dessa corrente filosófica - sentenças com valor de verdade podem ser tanto empíricas quanto analíticas. Grosso modo, portanto, o positivismo lógico apresentou-se como uma tentativa de unir racionalismo e empirismo num projeto epistemológico comum ${ }^{4}$. Moore (1985) apresenta um conjunto de sentenças que, julgamos, representam de forma bastante acurada o que podemos chamar de "princípios comuns” aos representantes do positivismo lógico:

a) que os métodos da ciência são a única via para o conhecimento válido, e que os métodos da ciência partem do estabelecimento do significado de uma proposição sobre a natureza, por meio da especificação do método de sua verificação experimental; proposições que não podem ser verificadas experiencialmente simplesmente não têm significado para a ciência;

b) que a ciência não é nada mais do que a reflexão conceitual sobre os conteúdos da experiência imediata de um cientista, e que afirmações científicas devem, portanto, ser interpretadas como proposições que reportam o que é dado na experiência imediata do cientista;

c) que reivindicações de conhecimento baseadas em elementos a priori, metafisicamente dados, devem ser

3 Surpreendentemente, talvez, o positivismo de Comte teve grande repercussão no Brasil ao final do século 19 e início do século 20 (Porto, 1987). Nosso país foi o único, além da França, a abrigar um templo positivista (a Igreja Positivista do Brasil, fundada por Miguel Lemos, em 1881, no Rio de Janeiro, e ainda existente), e sua influência sobre o movimento republicano é largamente reconhecida - vide o dictum comteano "Ordem e Progresso", estampado na bandeira nacional.

4 A tentativa, obviamente, não era inédita - disso, Kant (1790/1999) é o exemplo mais óbvio. Talvez a própria incapacidade de reunir coerentemente esses dois aspectos supostamente distintos da produção do conhecimento científico - o lógico e o empírico - tenha precipitado a ruína do positivismo lógico enquanto corrente de pensamento na filosofia da ciência, como sugere Smith (1986). 
rejeitadas, visto que tais reivindicações não podem ser experiencialmente verificadas;

d) que toda a ciência pode ser unificada sob a análise de como os cientistas operam sobre os conteúdos de sua experiência imediata, e como eles empregam definições fisicalistas (i.e., procedimentos intersubjetivamente verificáveis e leituras intersubjetivamente verificáveis de medidores, marcadores e contadores) em apoio a seus conceitos; e

e) que a linguagem é um sistema sintático para estruturar o conhecimento, e que uma compreensão da expressão desse conhecimento exige, também, uma compreensão dos papéis da lógica e da sintaxe no que diz respeito à construção, substituição, transformação, redução e prova. (Moore, 1985, p. 54)

Rejeita-se, portanto, a especulação metafísica. O contato direto com a natureza oferece a base para a construção de proposições científicas com valor de verdade, e a manipulação lógica e sintática dessas proposições pode, por sua vez, gerar outras sentenças desse tipo - estas, por sua vez, devem ser novamente submetidas à experimentação, para que possam ser "confirmadas".

O primeiro princípio listado acima ajuda a explicar a aproximação entre o positivismo lógico e o operacionismo. Na verdade, o operacionismo tornou-se um "ismo" a despeito da vontade de P. W. Bridgman, físico americano que, em 1927, lançou The Logic of Modern Physics, livro no qual expõe o que denominou tão-somente como uma "atitude" operacional em relação ao método científico. Assim como o positivismo lógico, o operacionismo foi uma tentativa de revisão de certos pressupostos epistemológicos e metodológicos diante das novas descobertas da física no início do século 20 - Bridgman cita Einstein com frequência, e parece mesmo responsabilizá-lo pela "nova atitude". O livro tem início com as seguintes palavras:

Um dos mais notáveis movimentos na física recente é uma mudança de atitude em direção ao que pode ser chamado de aspecto interpretativo da física. Reconhece-se, cada vez mais, tanto nos escritos quanto nos diálogos dos físicos, que o mundo da experimentação não é compreensivel sem algum exame do propósito da física e da natureza de seus conceitos fundamentais. (Bridgman, 1927, p. 1)

Como se tornou comum afirmar, não existe o "dado", mas o "construído": experimentador e objeto de estudo não podem ser artificialmente distinguidos - ou, novamente de acordo com Bridgman (1927), "todo o nosso conhecimento experimental e nossa compreensão da natureza é impossível e não-existente à parte de nossos próprios processos mentais", embora o autor aceite, simultaneamente, "nosso julgamento de senso comum de que há um mundo externo a nós" (p. 3). Contudo, Bridgman não estava saudando incondicionalmente as reflexões epistemológicas motivadas pelas novas descobertas da física. Pelo contrário, parecia ver seu próprio trabalho como um "mal necessário" a fim de reestabelecer certo equilíbrio e continuidade à física. Bridgman foi, nesse sentido, algo como um revolucionário que não gostava de revoluções:
Devemos agora tornar nosso trabalho a compreensão tão completa do caráter de nossas relações mentais permanentes com a natureza que outra mudança em nossa atitude, tal como aquela devida a Einstein, seja para sempre impossivel. Talvez tenha sido perdoável que uma revolução de atitude mental pudesse ocorrer uma vez, porque, afinal, a física é uma ciência jovem, e os físicos têm estado bastante ocupados, mas certamente seria censurável se tal revolução viesse a se provar necessária novamente. (Bridgman,1927, pp. 3-4)

Mas o que é, afinal, a "atitude operacional" proposta por Bridgman? A física, até o século 20, caracterizava-se, grosso modo, por uma postura realista (embora nem sempre deliberada): julgava descrever propriedades do mundo "tal como ele é". A contribuição de Einstein, de acordo com Bridgman, consistiu justamente em mostrar que os novos conceitos da física não poderiam ser descritos independentemente da relação do observador com os eventos que observa. Para Bridgman, portanto, os conceitos da física não devem tentar descrever propriedades dos objetos físicos; devem ser descrições das operações que os físicos executam a fim de determinar os valores atribuídos aos próprios conceitos. O exemplo clássico de Bridgman (1927) refere-se ao conceito de comprimento:

O que queremos dizer com o comprimento de um objeto? Nós, evidentemente, sabemos o que queremos dizer com comprimento se podemos dizer qual é o tamanho de todo e qualquer objeto, e para o físico nada mais é preciso. Para saber o comprimento de um objeto, devemos executar certas operações físicas. $O$ conceito de comprimento é, portanto, fixado quando as operações pelas quais o comprimento é medido são fixadas: isto é, o conceito de comprimento envolve tanto quanto, e nada mais, do que o conjunto de operações pelas quais o comprimento é determinado. Em geral, queremos dizer com qualquer conceito nada mais do que um conjunto de operações; o conceito é sinônimo de um conjunto correspondente de operações. (p. 5)

A proposta de Bridgman foi, sem dúvida, ousada. A "responsabilidade" pela definição de um conceito não mais pertence à natureza "como ela é", mas ao cientista que estuda a natureza de certas formas; caso essas formas mudem, os conceitos devem, também eles, mudar. Em consonância com o positivismo lógico, Bridgman afirma que existem questões significativas e não-significativas. As primeiras são passíveis de solução experimental; as segundas, não. E acrescenta o autor:

Creio que muitas das questões feitas sobre temas sociais e filosóficos serão consideradas sem significado quando examinadas do ponto de vista das operações. Sem dúvida, teríamos como resultado maior clareza de pensamento se o modo operacional de pensar fosse adotado em todos os campos de investigação, assim como na física. (Bridgman,1927, p. 17)

Para além do saber científico, Bridgman, apesar de reconhecer a complexidade prática da aplicação da atitude operacional mesmo no campo restrito da física, acaba por clamar, de forma surpreendente, por uma espécie de "reforma operacional" de amplo alcance, abrangendo todos os aspectos da vida cotidiana: 
O pensamento operacional irá, a princípio, provar-se uma virtude anti-social; uma pessoa pode ver-se perpetuamente incapaz de compreender a mais simples conversa com seus amigos, $e$ tornar-se-á universalmente impopular ao exigir o significado dos termos aparentemente simples de cada argumento. Possivelmente, depois que todos tiverem se treinado nesta forma preferencial, restará uma permanente tendência anti-social, pois sem dúvida muito de nossa conversação atual tornar-se-á desnecessária. O socialmente otimista pode atrever-se a esperar, contudo, que o efeito final será liberar nossas energias para um intercâmbio de idéias mais estimulante e interessante. Não apenas irá o pensamento operacional reformar a arte social da conversação, mas todas as nossas relações sociais estarão sujeitas a reforma. Permita-se a qualquer um examinar em termos operacionais qualquer discussão popular atual sobre religião ou questões morais para dar-se conta da magnitude da reforma que nos espera. (Bridgman,1927, pp. 18-19)

Estritamente falando, Bridgman não era um positivista lógico, e não apoiou sua proposta nessa filosofia. Foram os positivistas lógicos que viram na atitude operacional de Bridgman uma proposta complementar à do próprio positivismo lógico. $\mathrm{O}$ evento que sela a união das duas formas de pensamento ocorre em 1930: a chegada do filósofo austríaco H. Feigl, membro do Círculo de Viena, à Universidade de Harvard, na qual Bridgman também trabalhava. Foi Feigl quem introduziu os psicólogos de Harvard não só ao positivismo lógico, mas também à atitude operacional - entre eles, E. G. Boring e S. S. Stevens, que tornar-se-iam os principais divulgadores e defensores do operacionismo na psicologia norte-americana. O impacto do evento foi de grande monta: a psicologia norte-americana passou por uma "monumental revolução como conseqüência da aparição do operacionismo e do positivismo lógico no cenário intelectual" (Moore, 1985, p. 56). De fato, o operacionismo foi mais bem recebido entre os psicólogos do que entre os físicos, aos quais originalmente era destinado.

Boring e Stevens, esclareça-se, não faziam parte da tradição experimental behaviorista, ligada aos estudos sobre aprendizagem. Boring, aluno de E. B. Titchener, interessavase pelo estudo experimental das sensações ${ }^{5}$; Stevens, por sua vez, pode ser classificado como um psicofísico, embora tenha "pensado em si mesmo como algo próximo a um behaviorista" (Smith, 1995, p. 317). Apesar disso, ambos "conspicuamente identificaram o behaviorismo com o positivismo lógico" (Smith, 1995, p. 317). Stevens, por exemplo, classifica Purposive Behavior in Animals and Men, livro lançado por Tolman em 1932, como "um monumento na metodologia da definição" (1939/1976, p. 7).

Stevens, em especial, publicou uma série de artigos na década de 30, nos quais buscou apresentar aos psicólogos as idéias do operacionismo e do positivismo lógico. De acordo com Moore (1985), “o positivismo lógico e o operacionismo ... tornaram-se virtualmente sinônimos como marcos da nova epistemologia científica" (p. 56). Seria um erro, porém, aceitá-los como sinônimos. Bridgman, por exemplo, não

5 Boring também se tornou famoso como historiador da psicologia, sobretudo por meio de sua influente obra $A$ History of Experimental Psychology, originalmente lançada em 1929. apresentava nenhuma preocupação em analisar a lógica ou a sintaxe de enunciados científicos. Há diferenças notáveis também entre a "atitude operacional" de Bridgman e o "operacionismo” proposto por Stevens. Hardcastle (conforme citado por Ribes-Iñesta, 2003) reproduz palavras do próprio Bridgman que corroboram tal conclusão: “[Stevens] conversou extensivamente comigo sobre um par de textos seus antes de publicá-los, e professa ser um grande entusiasta das 'idéias operacionais' ... mas eu simplesmente não consigo fazê-lo ver que o que diz sobre 'ciência pública' e 'o outro' [the other one] é simplesmente distorcido" (p. 115). O operacionismo de Stevens é, claramente, uma versão particular da atitude operacional de Bridgman. Em alguns momentos, o próprio Stevens reconhece o fato - por exemplo, quando apresenta como primeiro princípio de sua versão do operacionismo a afirmação de que "a ciência, como a vemos, é um conjunto de proposições empíricas sobre as quais há acordo entre os membros da sociedade", reconhecendo, em seguida, que "Bridgman não concorda com esse critério social de conhecimento" (1939/1976, p. 8). De fato, a maior parte dos princípios apresentados por Stevens parece ser uma extensão em direção a assuntos dos quais Bridgman sequer buscou tratar, embora fossem familiares aos positivistas lógicos ${ }^{6}$.

Não queremos, aqui, traçar um quadro extensivo das diferenças entre Bridgman e Stevens - ou mais amplamente, entre o operacionismo e o positivismo lógico. Contudo, é importante notar que o operacionismo que veio a influenciar o mainstream da psicologia norte-americana não é, estritamente falando, uma doutrina bridgmaniana, senão uma versão particular da mesma, contendo diversas cláusulas adicionais - estas, provavelmente, devidas ao fato de que Boring e Stevens foram introduzidos ao operacionismo por um positivista lógico.

\section{Positivismo Lógico, Operacionismo e Neobehaviorismo}

Durante muito tempo, considerou-se os neobehaviorismos de Tolman, Hull e Skinner como expressões deliberadas do operacionismo e do positivismo lógico na Psicologia. Coube a Smith (1986) restabelecer a ordem histórica dos fatos:

A tese de que os behavioristas importaram suas metodologias do positivismo lógico é uma das principais afirmações da interpretação padrão. Cada um dos principais neobehavioristas, de fato, sustentou pontos de vista que eram similares a certos pontos de vista apresentados pelo positivismo lógico, e cada um deles

6 Acrescente-se, desde já, que o próprio Bridgman viria a "suavizar" algumas de suas posições, em resposta a seus críticos. Além disso, os mesmos positivistas lógicos que, por influência de Feigl, haviam se mostrado simpáticos à atitude operacional, acabariam por rejeitá-la, considerando-a uma "simplificação impraticável do problema extremamente intrincado do significado" (Green, 1992, p. 296). Diante das infindáveis polêmicas geradas em torno de suas idéias, Bridgman, em 1954, expressou sua aversão: "Sinto-me como se tivesse criado um Frankenstein, que certamente fugiu de meu alcance. Eu abomino a palavra operacionalismo ou operacionismo, que parece implicar um dogma, ou pelo menos uma tese de algum tipo. Aquilo que concebi é simples demais para ser dignificado com um nome tão pretensioso" (conforme citado por Green, 1992, p. 310). 
teve contatos pessoais significativos com figuras proeminentes no positivismo lógico. Porém, eles chegaram a seus pontos de vista antes do contato com o positivismo lógico, e a partir de perspectivas que eram muito diferentes daquelas do positivismo lógico. Assim, eles não precisaram importar seus pontos de vista metodológicos, porque tais pontos de vista já estavam desenvolvidos, pelos menos de forma geral, no contexto de seus próprios respectivos pressupostos sobre a epistemologia. De fato, tais pontos de vista foram, ocasionalmente, expressos subsequentemente na linguagem do positivismo lógico, mas a importação de terminologia não representa, no geral, um endosso aos pontos de vista do positivismo lógico. (Smith, 1986, p. 310)

A mesma interpretação vale, com algumas reservas ${ }^{7}$, para as relações dos neobehavioristas com o operacionismo - seja em sua versão original, seja na versão sustentada por Boring e Stevens (Smith, 1986).

Outro fato pode ter contribuído para os equívocos no que concerne a tais relações: as teorias neobehavioristas tiveram seu início e desenvolvimento na mesa época em que o positivismo lógico e o operacionismo exerceram sua maior influência. Contudo, não apenas os positivistas lógicos demonstraram interesse por outras teorias psicológicas além das variedades de behaviorismo da época, como os próprios neobehavioristas demonstraram interesse por outras filosofias da ciência, para além do positivismo lógico (Smith, 1986) ${ }^{8}$.

Talvez o leitor esteja se perguntando por que discorremos longamente sobre o positivismo lógico e o operacionismo se concluímos agora que essas doutrinas tiveram impacto restrito sobre os neobehavioristas? Contudo, a compreensão da natureza dessas filosofias é fundamental para contextualizar o evento que, salvo melhor julgamento, marcou o surgimento da filosofia behaviorista radical como a conhecemos. Trata-se do simpósio sobre operacionismo promovido pelo periódico Psychological Review em 1945. Instigado por Boring, o editor do periódico, H. S. Langfeld, convidou diversos nomes proeminentes da época para emitir opiniões sobre algumas das questões básicas concernentes ao tema - além dos já citados Bridgman, Boring, Feigl e Skinner, também H. E. Israel e C. Pratt. Talvez o principal mérito do simpósio tenha sido explicitar o considerável desacordo entre os participantes sobre as características do operacionismo (Green, 1992). Lopes Jr. (1992), ao analisar as contribuições dos participantes ao simpósio, conclui que, "o consenso verificado entre os psicólogos no reconhecimento da importância dos princípios operacionais, decididamente não se ampliou para a interpretação do que consistiam tais princípios" (p. 107).

7 A exceção, nesse caso, é Skinner, claramente influenciado pelo operacionismo de Bridgman em seus primeiros escritos, como veremos em breve.

8 É sempre recomendável repetir o alerta de Skinner quanto aos perigos engendrados pelas classificações a partir das categorias definidas pelos "ismos". Ao comentar sobre "os perigos inerentes em qualquer sistema de tipologia", Skinner afirma: "Há sempre uma tendência a argumentar que, porque indivíduos são similares em um aspecto, eles também são similares em outros" (1953/1965, p. 424). A fim de compreender os detalhes da obra de certo autor, nada substitui a análise detida da própria obra.
O próprio Skinner reconheceu a influência de Bridgman em sua obra inicial ${ }^{9}$ - por exemplo, em The Concept of the Reflex in the Description of Behavior (1931/1972), no qual admite também seu débito para com E. Mach e H. Poincaré. De fato, Skinner é apontado como pioneiro na análise operacional de um conceito psicológico (o conceito de reflexo) a partir da perspectiva operacional de Bridgman (Lopes Jr., 1992, p. 65) - e, conforme aponta Smith (1986), dado que Mach, Poincaré e Bridgman influenciaram também o positivismo lógico, "talvez não seja surpreendente que [Skinner] às vezes tenha mostrado um interesse no positivismo lógico" (p. 278). Além disso, em carta enviada a Stevens em 1935, Skinner elogia seu primeiro artigo sobre operacionismo, afirmando ser "essencialmente o que eu sempre supus que o behaviorismo representa" (Skinner, 1979/1984d, p. 163) - embora Skinner faça reparos ao artigo na mesma carta. A despeito desses fatos, porém,

... conforme a posição epistemológica própria de Skinner evoluiu gradualmente, suas opiniões sobre o operacionismo vieram a divergir agudamente daquelas dos positivistas lógicos ... Skinner pouco precisava de um positivismo lógico, pois, em 1930, ele já estava comprometido com uma variedade machiana de positivismo que, em seu impulso descritivo e biológico, acomodou seus vieses baconianos e darwinistas. (Smith, 1986, pp. 279-280) ${ }^{10}$

Para Skinner, o simpósio de 1945 ofereceu uma oportunidade conveniente para expor sua visão idiossincrática sobre o operacionismo, desfazendo definitivamente qualquer laço intelectual com psicólogos - como Boring e Stevens - que defendiam uma interpretação do operacionismo alicerçada no positivismo lógico (considerando, em especial, o fato de que essa interpretação insistia sobre o caráter público e "intersubjetivo" dos dados científicos). Sua contribuição foi publicada sob o título The Operational Analysis of Psychological Terms (1945/1984c). O argumento desenvolvido por Skinner apóia-se no que Smith (1986), apropriadamente, chamou de " 'bootstrap' nature of the epistemological enterprise" (p. 296), embora a passagem seja de difícil tradução. Zuriff (1980) expressa a ideia da seguinte forma: "Uma ciência do comportamento inevitavelmente volta-se para dentro de si mesma" (p. 337). Em outras palavras, uma ciência do comportamento aplica-se a todo e qualquer comportamento - inclusive o comportamento de pessoas que "olham para dentro de si mesmas" e utilizam termos psicológicos; inclusive o comportamento de cientistas que estudam esses e outros comportamentos. Por que não explicar também esses comportamentos por meio dos conceitos da própria ciência do comportamento?

9 As convergências e divergências entre Skinner e Bridgman são discutidas, por exemplo, em Lopes Jr. (1992). Como mostra esse autor, embora Skinner tenha abandonado a adesão estrita à análise operacional no sentido bridgmaniano que caracterizou sua obra inicial, algumas semelhanças entre as posições dos dois autores permanecem mesmo em 1945.

10 Para Smith (1995), é possível, diante disso, qualificar Skinner como um positivista - desde que não um positivista lógico, mas sim um positivista "descritivo, indutivo, não-lógico" (pp. 39-40). 
Talvez não se deva chamar a isso uma filosofia da ciência. Smith (1986), por exemplo, prefere a expressão "psicologia da ciência" - embora deixe claro que isso não distingue Skinner dos demais neobehavioristas, dado que Tolman e Hull também buscaram construir suas próprias "psicologias da ciência". Alternativamente, poderíamos qualificar o Behaviorismo Radical como uma filosofia psicológica: uma filosofia informada por dados produzidos pela Análise do Comportamento (Dittrich, 2005). A relação de conhecimento entre o cientista e seu objeto de investigação é, por si, um objeto de estudo legítimo no âmbito de uma ciência do comportamento (Abib, 1993; Skinner, 1963/1969, 1974, 1945/1984c; Zuriff, 1980). Conhecer o mundo - público ou privado - é comportar-se de certas formas em relação a ele e, assim, tanto o conhecimento de nosso "mundo interno" quanto a atividade científica (na Psicologia e em outras ciências) fazem parte do campo de interesses do analista do comportamento.

\section{O Operacionismo de Skinner}

A definição operacional de um termo psicológico, para Skinner, envolve a especificação das circunstâncias sob as quais o termo é emitido. Para o autor, obviamente, essa especificação obedece ao modelo estabelecido pela tríplice contingência. O artigo produzido por Skinner para o simpósio de 1945, baseou-se, em grande parte, no material que preparava para o livro Verbal Behavior, cuja publicação se daria somente 12 anos depois (Skinner, 1957). No artigo, Skinner descreve "quatro maneiras pelas quais a comunidade verbal, sem acesso a um estímulo privado, pode gerar comportamento verbal em resposta a ele" (1945/1984c, p. 549) ${ }^{11}$. Essa é, para Skinner, a forma adequada de definir operacionalmente os termos psicológicos: descrevendo as formas pelas quais as pessoas aprendem a utilizá-los.

Quanto aos termos utilizados pelos cientistas e lógicos, Skinner não oferece, nesse texto, exemplos de análise operacional, mas apenas a promessa de que ela, um dia, possa vir a ser realizada:

Para serem consistentes, os psicólogos devem lidar com suas próprias práticas verbais, desenvolvendo uma ciência empírica do comportamento verbal. ... Se nossa visão final do comportamento verbal invalidar nossa estrutura científica do ponto de vista da lógica e do valor de verdade, então tanto pior para a lógica, que também será absorvida por nossa análise. (1945/1984c, p. 551)

Trata-se de uma promessa arrojada - que, diga-se, ainda está longe de ser cumprida pelos behavioristas radicais. Mas

11 A saber: respostas verbais sob controle de estimulação privada podem (1) ser reforçadas pela comunidade quando esta observa indícios públicos da provável ocorrência de estimulação privada; (2) ser reforçadas pela comunidade quando esta observa respostas colaterais que provavelmente acompanham a estimulação privada; (3) derivar do reforçamento prévio de respostas verbais sob controle de respostas públicas, posteriormente executadas de forma privada; (4) derivar, via generalização, de propriedades comuns entre estímulos públicos e privados (caso no qual são chamadas “metáforas”). também é possível argumentar que os problemas da filosofia da ciência não serão resolvidos por uma teoria empírica do comportamento verbal, pois exigem, ainda assim, a análise conceitual no sentido filosófico "tradicional" (Harzem, 1984) - e, de fato, os próprios behavioristas radicais realizam esse tipo de análise com frequência. No mesmo espírito de argumentação, Meehl (1984) pergunta:

Por que Skinner quer reduzir os conceitos lógicos e epistemológicos de verdade e validade ao vocabulário behaviorista? ... Nós não reduzimos os conceitos da geometria, análise e teoria dos números ao comportamento dos matemáticos, e, de fato, não poderíamos operar nessas disciplinas se o fizéssemos, pois nosso conhecimento do comportamento matemático é muito primitivo, como estou certo que Skinner concordará. Por que, então, é necessário comportamentalizar a lógica? (p. 564)

A isso, Skinner (1984a) responde:

Eu não quero que os lógicos utilizem o vocabulário behaviorista, mas se eu for analisar o comportamento dos lógicos, eu devo usar os meus termos, não os deles. Os termos deles estão entre os objetos de análise. Estou disposto a usar 'verdadeiro' e 'falso'na lógica e na matemática, onde eles podem ser razoavelmente bem definidos. (p. 576)

O problema parece residir, conforme sugere Moore (1984), no fato de que a descrição da atividade de filósofos e cientistas, mesmo quando feita pelos próprios filósofos e cientistas é, via de regra, uma descrição mentalista. Isso se aplica aos operacionistas e aos positivistas lógicos. A proposta de Skinner é uma alternativa viável a tais descrições, ao tratar a filosofia e a ciência como atividades-em-contexto (Dittrich, 2005).

\section{O Behaviorismo Radical e a Observação do Comportamento}

O problema da observação dos fenômenos psicológicos acompanha a Psicologia em toda a sua história, e é decisivo para a definição das características das diferentes teorias nessa disciplina. Não se trata apenas de um problema relativo à observação dos eventos privados. Há mais de uma forma de observar também o comportamento público. Não existe uma observação “pura”, isenta de preconceitos, sobre qualquer objeto. Objetos são observados e descritos de diversas formas por espectadores diferentes, de acordo com suas experiências passadas e atuais - vale dizer, de acordo com as contingências de reforço passadas e atuais que controlam seu comportamento na situação observada e descrita (Skinner, 1953/1965, 1971, 1974). É preciso, por exemplo, aprender a observar contingências de reforço; elas não se oferecem à observação casual (Skinner, 1971).

No âmbito da Análise do Comportamento, a observação pública do comportamento, quando possível, é uma indiscutível vantagem. A observação permite - ou, ao menos, facilita - a previsão e o controle do comportamento - isto é, a manipulação de variáveis independentes e a observação de seus efeitos sobre as variáveis dependentes. Voltemos, 
agora, ao problema dos eventos privados. Supomos, os behavioristas radicais, que o "mundo interno" dos seres humanos é composto por eventos que podem ser descritos na linguagem da tríplice contingência: há estímulos (antecedentes ou consequentes) e respostas. Qual é a base para tal suposição - considerando que não podemos, a partir de uma perspectiva experimental, observar e, consequentemente, prever e controlar tais eventos com o rigor necessário? Trata-se de uma interpretação. Eis a forma como Skinner (1984a) define a palavra: "Eu a definiria com o uso de termos e princípios científicos para falar de fatos sobre os quais sabe-se muito pouco para tornar possíveis a previsão e o controle” (p. 578) $)^{12}$. As "ferramentas" interpretativas - isto é, os "termos e princípios científicos" aos quais se refere Skinner - são aqueles que, no âmbito da análise experimental do comportamento, são utilizados para descrever as diferentes formas de interação comportamento-ambiente.

Diante da definição de Skinner, torna-se óbvio que a Análise do Comportamento é, em grande medida, um exercício de interpretação. As explicações de Skinner para comportamentos humanos complexos (o comportamento verbal, as interações sociais, a auto-observação e o autocontrole) são explicações interpretativas. Note-se, contudo, que a interpretação, assim definida, é uma prática comum e necessária também a outras ciências.

A “análise operacional de termos psicológicos” apresentada por Skinner também é uma interpretação. $\mathrm{O}$ fato de que é uma interpretação que inclui eventos não observados acrescenta certas dificuldades. Parte da responsabilidade pela profusão de interpretações psicológicas sobre os eventos privados deve-se, sem dúvida, ao próprio caráter privado de tais eventos:

Não há nada de errado com uma explicação interna como tal, mas eventos localizados no interior de um sistema tendem a ser dificeis de observar. Por esta razão, somos encorajados a conferir-lhes propriedades sem justificação. Pior ainda, podemos inventar causas deste tipo sem medo de contradição. (Skinner, 1953/1965, p. 27)

A privacidade, obviamente, dificulta as investigações também no âmbito da Análise do Comportamento. Ao discorrer sobre os possíveis controles da resposta verbal "Meu dente dói”, Skinner (1945/1984c) afirma:

A primeira dificuldade é que não podemos, como no caso do estímulo público, explicar a resposta verbal apontando para um estímulo controlador. Nossa prática é inferir o evento privado, mas isso se opõe à direção investigativa em uma ciência do comportamento, na qual devemos prever a resposta através,

12 Em Beyond Freedom and Dignity, encontramos uma definição semelhante: "Muitas vezes referimo-nos a coisas que não podemos observar ou medir com a precisão demandada por uma análise científica, e, ao fazê-lo, há muito a se ganhar ao usar termos e princípios que foram forjados em condições mais precisas" (Skinner, 1971, pp. 22-23). Dito de outra forma: onde a experimentação não é possível, utilize-se a interpretação - mas uma interpretação baseada em resultados experimentais. Estamos, portanto, interpretando o não-observável a partir do observável. entre outras coisas, de um conhecimento independente do estimulo. (p..548)

Esse conhecimento independente é impossível. Não obstante, Skinner não se furta a realizar interpretações sobre os eventos privados, a despeito da impossibilidade de uma análise experimental. Alguns aspectos concernentes à interpretação skinneriana merecem comentário. Em primeiro lugar, Skinner não espera construir uma taxonomia exaustiva e precisa dos eventos privados, que retrate o mundo interno "como ele realmente é"13. Isso é impossível, por definição. Diferentes comunidades verbais criam diferentes níveis e formas de "conhecer-se a si mesmo", e a privacidade dos eventos privados impede o reforçamento diferencial necessário para a criação de um vocabulário inequívoco sobre os mesmos (Skinner, 1945/1984c). Em segundo lugar, Skinner, estritamente falando, não está falando sobre fenômenos que não pode observar: ele pode observá-los em si mesmo. Na verdade, se Skinner não observasse seu próprio mundo privado, toda a sua interpretação sobre os eventos privados seria impossível - visto que, nessas condições, Skinner não teria acesso a nenhum mundo privado, e não poderia, portanto, ter qualquer conhecimento dos estímulos que controlam respostas verbais como "pensar” e "sentir”, por exemplo. Ao menos nesse sentido - restrito, sem dúvidas -, a introspecção é não apenas objeto, mas também método para Skinner. Considerese, por exemplo, as seguintes afirmações do autor: "Não há, é claro, nenhuma dúvida sobre se respostas a estímulos privados são possíveis. Elas ocorrem de modo suficientemente comum, e devem ser explicadas" (Skinner, 1945/1984c, p. 549). Tendemos, os behavioristas radicais, a concordar com Skinner, por dois motivos: (1) porque a linguagem da Análise do Comportamento nos é familiar; (2) porque observamos em nós mesmos respostas a estímulos privados - visto que não podemos, por definição, observá-las em mais ninguém (Podemos observar alguém dizendo "Meu dente dói", mas não podemos observar a dor que, supostamente, controla a resposta.). Quando Skinner afirma, na passagem acima, que "não há nenhuma dúvida", apóia sua certeza na auto-observação, e busca a anuência de leitores que também observam apenas seus próprios mundos privados.

Alguns comentários adicionais, porém, são importantes nesse momento. Em primeiro lugar, o fato de que Skinner precisou exercer a auto-observação para que pudesse falar de eventos privados não significa que tenha considerado seu próprio "mundo interno" como um modelo ideal dos "mundos internos" de toda a humanidade. Como vimos há pouco, Skinner é o primeiro a reconhecer que a forma como falamos sobre nossos eventos privados (bem como sobre eventos públicos) é necessariamente aprendida, e que uma linguagem que descreva os eventos privados de forma unívoca é impossível. Não apenas pensamos e sentimos de formas diferentes, mas descrevemos o pensar e o sentir de formas diferentes. Alguém talvez possa afirmar que mesmo as referências genéricas de Skinner a pensamentos e sentimentos são necessariamente "subjetivas”, culturalmente construídas, típicas das comunidades verbais que ensinaram o próprio

13 Lembremo-nos que a psicologia já se prestou a tentativas dessa ordem. O estruturalismo de Titchener foi, nesse sentido, emblemático. 
Skinner a descrever seu "mundo interno". Certamente o são - mas isso se aplica a qualquer forma de descrição, seja de eventos públicos ou privados. O erro está em insistir na busca por uma linguagem neutra, que descreva o que os eventos privados "realmente são": "Uma ciência independente da subjetividade seria uma ciência independente de comunidades verbais" (Skinner, 1974, p. 221).

Em segundo lugar, a distinção entre eventos públicos e privados, embora necessária, não deve servir, no âmbito do Behaviorismo Radical, para estabelecer barreiras rígidas entre tais eventos. Pelo contrário: ao tratar eventos comportamentais (entre eles, pensamentos e sentimentos) como relações de controle entre estímulos e respostas, sejam públicos ou privados, o Behaviorismo Radical contribui para dissolver tais barreiras, mostrando que "a linha entre público e privado não é fixa" (Skinner, 1953/1965, p. 282) e que, portanto, "a pele não é tão importante enquanto fronteira" (Skinner, 1963/1969, p. 228). A existência de um "mundo interno" só pode ser explicada pela relação de um organismo com seu "mundo externo", uma vez que respostas privadas e descrições de eventos privados só podem surgir quando adequadamente modelados por comunidades verbais. Por fim, como nota Tourinho (2006), "uma resposta do organismo como um todo não é simplesmente observável ou inobservável. Qualquer resposta pode variar ao longo de um contínuo de observabilidade”. (p. 555)

Assim, o Skinner que observa seus próprios eventos privados e utiliza tal observação como um dos subsídios mas não o único - de uma interpretação comportamental da privacidade é, também ele, um produto das contingências mantidas pelas comunidades verbais que modelaram seu comportamento - algo que o próprio autor não tem nenhuma dificuldade em reconhecer (e. g., Skinner, 1957, pp. 453-456; 1974, pp. 247-248; 1983/1984b, p. 400). Se é possível concordar quanto ao fato de que a introspecção foi, no sentido apontado acima, um recurso metodológico para Skinner, certamente não se trata, por outro lado, de aproximá-lo do cogito ergo sum cartesiano, ou das tradições psicológicas que utilizaram e utilizam a introspecção como método privilegiado de acesso à "mente" ou à "subjetividade", tratando-as como objetos à parte do comportamento e de suas relações com o mundo "externo".

\section{Considerações Finais}

A análise operacional de termos psicológicos proposta por Skinner é uma interpretação analítico-comportamental das circunstâncias sob as quais os termos psicológicos são empregados. Como em muitos casos tais circunstâncias são, ao menos em parte, inobserváveis publicamente, Skinner teve, necessariamente, que recorrer à auto-observação para construir sua interpretação. Quando Skinner estende essa interpretação a outras pessoas, está, necessariamente, inferindo a existência, no mundo privado de tais pessoas, de processos semelhantes, em alguma medida, aos que observa em si mesmo. Em resumo, portanto, a explicação de Skinner para os eventos privados: (1) é uma interpretação; (2) refere-se, em parte, a eventos inobserváveis publicamente; (3) deve, portanto, em alguma medida, utilizar a introspecção enquanto método; (4) deve, portanto, em alguma medida, lançar mão de inferências sobre o mundo privado do outro.

Tais conclusões, vale notar, aplicam-se não apenas a Skinner, mas a qualquer pessoa que se proponha a falar sobre eventos privados. Assim, talvez o apelo de Skinner (1971) para que nos voltemos "do inferido para o observado, do miraculoso para o natural, do inacessível para o manipulável” (p. 201) seja passível de reparo. O próprio Skinner discorreu com freqüência sobre eventos inferidos - sem, contudo, considerá-los "miraculosos". Esse é um dos diferenciais da filosofia behaviorista radical, e deve ser preservado.

Sempre que possível, a observação pública de eventos comportamentais é desejável ${ }^{14}$. Mas o analista do comportamento - como aponta explicitamente o próprio Skinner (1963/1969, pp. 227-228) - não deve dar as costas a fenômenos que não pode observar ou medir. Se a interpretação é, como quer Skinner, parte da ciência, não temos qualquer motivo para rejeitá-la.

\section{Referências}

Abib, J. A. D. (1993). “A psicologia é ciência?” Ciência é articulação de discursos da filosofia, da história da ciência e da psicologia. Psicologia: Teoria e Pesquisa, 9, 465-486.

Bridgman, P. W. (1927). The logic of modern physics. New York: Macmillan. Retirado em 03/08/06, de http://www.marxists. org/reference/subject/philosophy/works/us/bridgman.htm

Cupani, A. (1990). Positivismo, "positivismo" e objetividade científica. Reflexão, 46, 103-107.

Dittrich, A. (2005). A atividade científica como objeto da ciência: Uma perspectiva contextualista behaviorista radical. Em Setor de Ciências Humanas, Letras e Artes - UFPR (Org.), Anais do III Encontro da Rede Paranaense de Pesquisa em História e Filosofia da Ciência (pp. 14-27). Curitiba: UFPR.

Gioia, S. C. (2004). A razão, a experiência e a construção de um universo geométrico: Galileu Galilei. Em M. A. Andery, N. Micheletto, T. M. P. Sério, D. R. Rubano, M. Moroz, M. E. Pereira, S. C. Gioia, M. Gianfaldoni, M. R. Savioli \& M. L. Zanotto (Orgs.), Para compreender a ciência: Uma perspectiva histórica (pp. 179191). Rio de Janeiro: Garamond; São Paulo: EDUC. (Trabalho original publicado em 1988)

Green, C. D. (1992). Of immortal mythological beasts: Operationism in psychology. Theory \& Psychology, 2, 291-320.

14 Diante do fato óbvio de que, em muitas ocasiões, tal observação pública não é possível, os cursos de ação são discutíveis. A praxe da Análise do Comportamento tem sido evitar o estudo experimental de tais eventos, "examinando o terceiro elo como uma função do primeiro", como sugeriu Skinner (1953/1965, p. 35) - isto é, estudando as relações funcionais entre estímulos públicos e respostas públicas. O procedimento é útil por diversos motivos, mas dificulta o estudo experimental de comportamentos como pensar, por exemplo. Contudo, estratégias criativas para a "publicização" de tais comportamentos têm sido propostas (e. g., Simonassi, Tourinho \& Silva, 2001), mas elas envolvem, necessariamente, o uso de inferências. Assim, conforme reconhecem os autores, estudos desse tipo são “inovadores e não se amparam em delineamentos já consagrados como produtivos” (p. 135). A despeito do resultado das discussões sobre o tema, o surgimento de novas propostas para o avanço da análise experimental é, sem dúvida, desejável, e ilustra a íntima conexão entre filosofia e método na Análise do Comportamento. 
Harzem, P. (1984). Operationism, smuggled connotations and the nothing-else clause. The Behavioral and Brain Sciences, 7, 559.

Kant, I. (1999). Crítica da razão pura (V. Rohden \& U. Moosburger, Trads.). São Paulo: Nova Cultural. (Trabalho original publicado em 1790)

Lopes Jr., J. (1992). Sobre os critérios de interpretação da história do behaviorismo radical (1930-1945): Operacionismo e privacidade. Dissertação de Mestrado, Universidade de São Paulo, São Paulo.

Meehl, P. E. (1984). Radical behaviorism and mental events: Four methodological queries. The Behavioral and Brain Sciences, 7, 563-564.

Moore, J. (1984). On privacy, causes and contingencies. The Behavior Analyst, 7, 3-16.

Moore, J. (1985). Some historical and conceptual relations among logical positivism, operationism, and behaviorism. The Behavior Analyst, 8, 53-63.

Porto, A. (1987). Positivismo e seus dilemas. Ciência Hoje, 6, 55-61.

Ribes-Iñesta, E. (2003). What is defined in operational definitions? The case of operant psychology. Behavior and Philosophy, 31, 111-126.

Simonassi, L. E., Tourinho, E. Z., \& Silva, A. V. (2001). Comportamento privado: Acessibilidade e relação com comportamento público. Psicologia: Reflexão e Crítica, 14, 133142.

Skinner, B. F. (1957). Verbal behavior. New York: AppletonCentury-Crofts.

Skinner, B. F. (1965). Science and human behavior. New York: Macmillan. (Trabalho original publicado em 1953)

Skinner, B. F. (1969). Behaviorism at fifty. Em B. F. Skinner, Contingencies of reinforcement: A theoretical analysis (pp. 221268). New York: Appleton-Century-Crofts. (Trabalho original publicado em 1963)

Skinner, B. F. (1971). Beyond freedom and dignity. New York: Alfred A. Knopf.

Skinner, B. F. (1972). The concept of the reflex in the description of behavior. Em B. F. Skinner, Cumulative record: A selection of papers (pp. 429-457). New York: Appleton-Century-Crofts. (Trabalho original publicado em 1931)
Skinner, B. F. (1974). About behaviorism. New York: Alfred A. Knopf.

Skinner, B. F. (1984a). Coming to terms with private events. The Behavioral and Brain Sciences, 7, 572-579.

Skinner, B. F. (1984b). A matter of consequences: Part three of an autobiography. New York: New York University Press. (Trabalho original publicado em 1983)

Skinner, B. F. (1984c). The operational analysis of psychological terms. The Behavioral and Brain Sciences, 7, 547-553. (Trabalho original publicado em 1945)

Skinner, B. F. (1984d). The shaping of a behaviorist: Part two of an autobiography. New York: New York University Press. (Trabalho original publicado em 1979)

Smith, L. D. (1986). Behaviorism and logical positivism: A reassessment of the alliance. Stanford, CA: Stanford University Press.

Smith, L. D. (1995). Inquiry nearer the source: Bacon, Mach, and The Behavior of Organisms. Em J. T. Todd \& E. K. Morris (Orgs.), Modern perspectives on B. F. Skinner and contemporary behaviorism (pp. 39-50). Westport, CT: Greenwood Press.

Stevens, S. S. (1976). Operationism and logical positivism. Em M. H. Marx \& F. E. Goodson (Orgs.), Theories in contemporary psychology (pp. 2-31). New York: Macmillan. (Trabalho original publicado em 1939)

Tourinho, E. Z. (2006). On the distinction between private events and the physiology of the organism. The Behavior Analyst Today, 7, 548-559.

Zuriff, G. E. (1980). Radical behaviorist epistemology. Psychological Bulletin, 87, 337-350. 